\title{
Research on Teaching Scheme of Introduction to Engineering Management Based on the EPMI
}

\author{
Hualong $\mathrm{Cai}^{1}$, Ming Ouyang ${ }^{1, *}$, Chengyu $\mathrm{Zhu}^{1}$ and Chen Peng ${ }^{1}$ \\ ${ }^{1}$ School of Civil Engineering, Jiaying University, Meizhou, Guangdong, 514015, China
}

\begin{abstract}
Introduction to Engineering Management is recognized as the first enlightening course for freshmen majoring in engineering management. Its teaching effect significantly impacts the cultivation of engineering management professionals. The engineering management professional certification management information platform refers to EPMI. By complying with the EPMI, this study investigates the teaching system of the ideological and political education of the course, teaching mode and teaching feedback mechanism. Compared with existing conventional teaching scheme, the novel teaching scheme enriches the content and form of the course, promotes the curriculum teaching system more systematic and scientific, helps students further clarify the focus of professional learning, which enables them to achieve the curriculum teaching goals more effectively.
\end{abstract}

\section{Background of research}

Introduction to Engineering Management is considered a vital and professional enlightenment course for freshmen majoring in engineering management. In addition, it undertakes multiple tasks (e.g., professional direction guidance and interest promotion) in the talent training program of engineering management. In the context of the country's in-depth implementation of major strategic developments (e.g., innovation-driven development and Internet + ), informatization teaching has become an important direction of the teaching reform of various subjects. It is noteworthy that during a public emergency (e.g., pandemic of coronavirus disease), the conventional classroom teaching model cannot achieve normal teaching. Accordingly, the teaching of this course urgently requires a platform capable of meeting the teaching requirements and achieving the teaching goals, as well as adapting to the trend of informatization teaching. The EPMI has been formed and implemented.

\section{Course teaching goals and current problems}

In combination with the school's orientation, development status, academic situation analysis and talent training requirements, the school has set the teaching goal of engineering management personnel training. Given the study on the course of Introduction to Engineering Management, the curricular objectives of three layers (i.e., theoretical knowledge, practical ability and engineering literacy) should be fully achieved. The theoretical knowledge goal refers to training students to understand the development of engineering management and clarify the professional scope of engineering management, combining all aspects of management, economics, laws and regulations to become familiar with and master the basic concepts of engineering, basic theory and method, as an attempt to expand engineering horizons and broaden subject knowledge. Practical ability goal is to train students to initially develop thinking and methods for tackling down practical engineering problems, and be capable of exploiting the knowledge they have learned to qualitatively and quantitatively solve engineering problems. Engineering literacy goals include training in engineering industry professional pride of the students, firmly establishing students' sustainable development concepts and innovative consciousness, and nurturing students' strong home country feelings.

Based on full teaching discussion and research, combined with previous practical teaching experience of this course, the problems of this course are mainly reflected in four aspects: (1) Insufficient teaching integration, low level of informatization, and not getting rid of the conventional teaching mode; (2) In the engineering life cycle, insufficient insight in gained into forward-looking knowledge, and system processes are insufficiently understood and mastered; (3) The integration of theoretical knowledge and practice is insufficient, and the teaching form is single; (4) Innovation consciousness, engineering responsibility consciousness and sustainable development concept are insufficiently nurtured (Figure 1). 


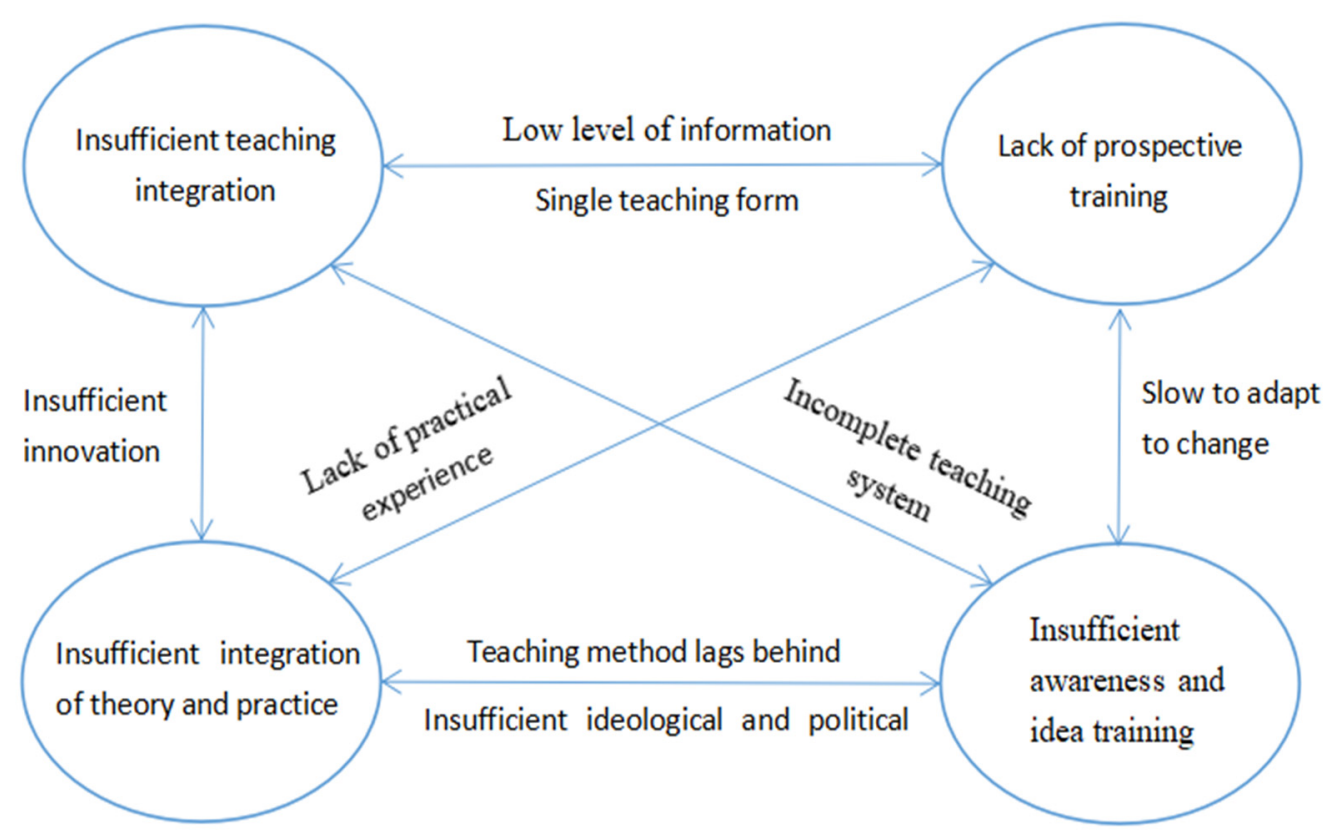

Figure 1. Current teaching problems

\section{Course teaching scheme based on the EPMI}

\subsection{Based on the New Engineering Subject, build a characteristic ideological and political education system}

The New Engineering Subject implies that it is upheld to foster virtue through education, with the construction concept of responding to changes and shaping the future, take inheritance and innovation, intersection and integration, coordination and sharing as the main ways, as well as train future diversified and innovative engineers of excellence [1]. By complying with this connotation, the characteristic ideological and political education system of Red-Yellow-Green three-color [2] fusions for Introduction to Engineering Management is implemented via the EPMI.

Red refers to red gene. Given the characteristics of fast data transmission speed of information platform, on the information platform, the "red" element of moral education in the course teaching system of Introduction to Engineering Management should be vigorously promoted to emphasize the importance of in-depth exploration of red gene culture for engineering construction, publicize and explain the patriotic stories of the revolutionary ancestors, advocate and guide the revolutionary ancestors to learn.

Yellow indicates yellow line of thinking. The information platform is capable of collecting information and monitoring the entire process of engineering. Via the information platform, soliciting papers and publicizing activities on engineering responsibility consciousness, safety bottom line thinking and safety responsibility consciousness should be carried out, and then the students' cognitive level should be collected and analyzed.

Green refers to the green thinking. Through the information platform, this study performs the story collection and the knowledge competition of new development concept, innovation awareness and sustainable development concept (Figure 2). 


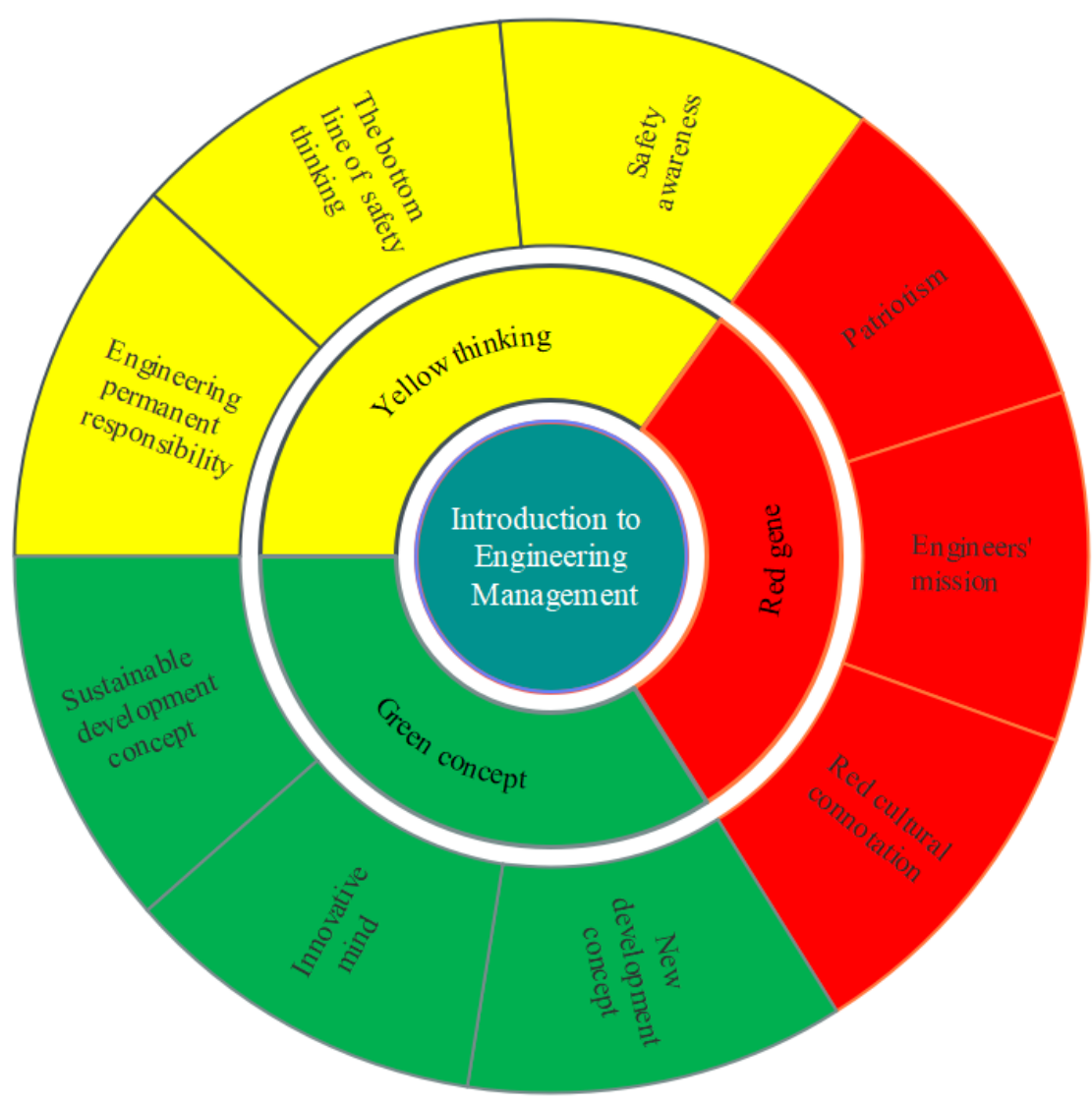

Figure 2. System of ideological and political education

\subsection{Information teaching mode}

When novel coronavirus pneumonia outbreak occurs, the conventional teaching mode cannot be implemented. The EPMI provides online teaching platform and develops three functional modules, enriching the teaching content, strengthening the cultivation of practical ability and introducing the examination center system.

\subsubsection{Meet the need of teaching, develop functional modules.}

To more effectively implement the teaching thinking of "taking the teaching demand as the guidance and the teaching goal as the driving force", the building of the information-based teaching mode of the course should be expedited to satisfy students' learning needs, and students' innovative vitality should be stimulated. The EPMI develops three functional modules, i.e., student information management, teacher information management and teaching resource management (Figure 3).

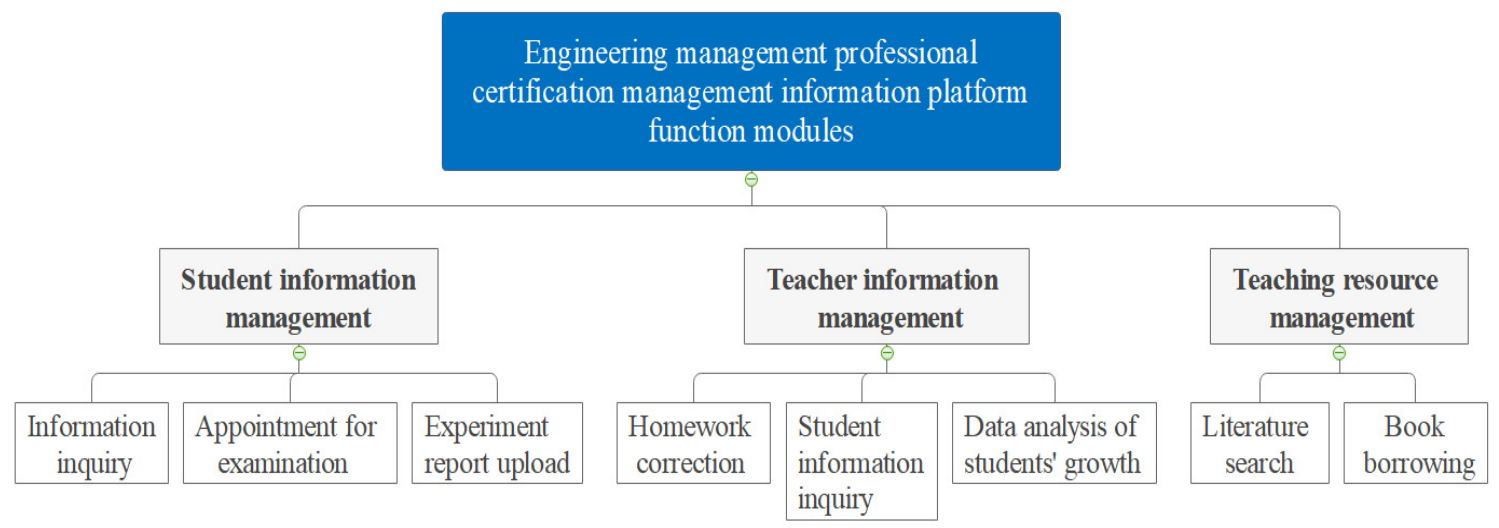

Figure 3. Three functional modules 
The function module of student information management is capable of satisfying the needs of student information query, examination appointment, class assignment and experiment report upload. Moreover, the teacher information management function module can satisfy the needs of teachers in terms of students' homework correction, information query, course learning progress, growth data analysis, etc. The function module of teaching resource management can be employed to search literature and borrow books.

3.2.2 Enrich teaching content and strengthen practical ability. Several high-quality teaching resources collected by teachers from MOOC, Tencent video and other network platforms [3] can be uploaded to the information platform together with many cutting-edge knowledge regarding the course. Students are enabled to ask questions on the information platform, and teachers can answer students' questions on the information platform.

By using on-campus training base, off campus practice and others, students will gain a preliminary insight into engineering materials, architectural design and other knowledge in a real engineering environment. The autonomous learning ability and the ability to solve practical engineering problems of students will be enhanced in depth ${ }^{[4]}$. After the internship, students upload information (e.g., photos, videos and internship reports) to the EPMI. The information platform will automatically save and backup the information uploaded by students.

\subsubsection{Have an examination center system to complete the final assessment.}

EPMI is equipped with an examination center system which exhibits a perfect structure and is capable of controlling examination process and anti-cheating. The system supports multiple question types, various test entry methods as well as test paper composition methods; it also provides a wide range of support platform options (e.g., PC terminal and WeChat applet).

Before the final exam, examinees make an appointment for the exam and check the location and seat of the exam. During the formal examination, examinees should enter the examination center within the prescribed examination time. After the examinee's name and student number are entered, the system will perform facial recognition on the examinees. After the examinees' information is checked in the information database of the examination center, the examinees can answer the test paper.

When examinees answer the test paper, the system will record their answering process in real-time video and archive the process automatically. If the examinees who are answering the test paper find there is something wrong with the test paper, they can click the system specific button to ask the invigilator for help.

After the examinees have finished answering the test paper, they only need to select the submit answer button to complete the submission. After the test paper is submitted, objective questions will be automatically corrected by the system, while subjective questions will receive the correction by the teachers. After the correction of the entire test paper is completed, the system automatically calculates the final grade (Figure 4).

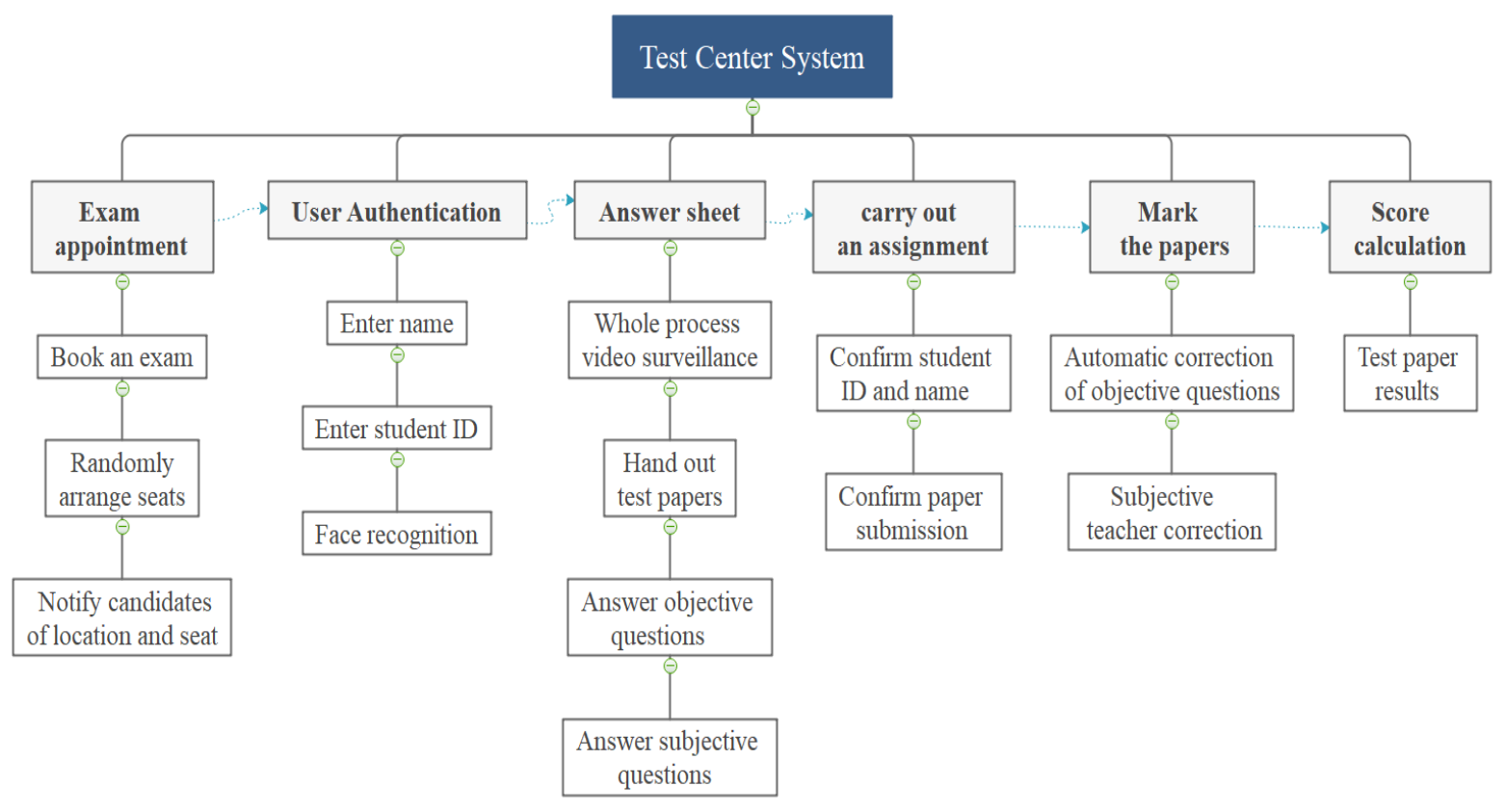

Figure 4. System structure diagram of examination center 


\subsection{Feedback mechanism of teaching information}

The EPMI has a perfect teaching information feedback mechanism, comprising information gathering-teaching evaluation-performance analysis and feedback.

\subsubsection{Information gathering.}

The EPMI utilizes Html and Css to make the front desk of the system. It exploits PHP language to write background business logic. The Mysql database is adopted to store the students' daily homework, internship reports, examinations and other data of the course. The stored data is decomposed by complying with functional modules and levels in a multi-modular prototype design style and then transmitted to the corresponding functional sections for gathering information.

\subsubsection{Teaching evaluation.}

Students' comprehensive teaching evaluation is divided into three parts: theoretical knowledge, practical ability and engineering literacy. To be specific, theoretical knowledge takes up 50 points, practical ability accounts for 30 points, and engineering literacy achieves 20 points.

Theoretical knowledge: final exam scores take up 40 points, preview situation, classroom interaction participation, homework completion and others ${ }^{[5]}$ account for 10 points;

Practical ability: composed of internship report, experiment completion, scientific research competition and others, accounting for 30 points;

Engineering literacy: the activeness of students participating in ideological and political education activities on the information platform, student group evaluation, teacher evaluation and others, accounting for 20 points.

\subsubsection{Performance analysis and feedback.}

Based on the students' teaching evaluation, the EPMI conducts data analysis on students' theoretical knowledge, practical ability and engineering literacy to generate bar chart, line chart and other graphics to show the actual situation of students' assessment results. For students' problems, the information platform will give feedback to students and propose the corresponding specific improvement measures. In addition, students are allowed to feed back their teaching opinions to teachers via the information platform, and teachers can also inquire about students' specific learning situation.

\section{Teaching effect based on the EPMI}

Compared with the conventional teaching scheme of the course, after the novel teaching scheme based on the EPMI, it is found that the novel teaching scheme is more effective than the conventional scheme. From the discovery, the students' professional theoretical knowledge level has been significantly improved. Moreover, their practical experience has been more abundant and their ability to address practical engineering problems has been significantly enhanced. It is noteworthy that, the students' awareness of Engineering responsibility and innovation had been noticeably strengthened, as well as the sense of professional honor in the engineering industry, and students gain more insights into cutting-edge scientific knowledge. Notably, the understanding and mastery of system processes has been substantially optimized during the engineering life cycle.

\section{Conclusion}

As the first professional basic course for engineering management students, the course Introduction to Engineering Management is of enlightening, leading and forward-looking significance. The EPMI satisfies the actual needs of the course teaching, and it stresses the comprehensive realization of the three-level objectives of theoretical knowledge, practical ability and engineering literacy. By complying with the EPMI, this study investigates the teaching scheme of the course, and successfully builds the curriculum information teaching system that integrates ideological and political education, teaching mode and teaching feedback mechanism. It is practically demonstrated that the novel teaching scheme elevates the level of students' Ideological and political education. It facilitates the improvement of students' theoretical knowledge, practical ability and engineering literacy, as well as the perfection of the curriculum information teaching system, which helps achieve the curriculum teaching goals completely.

\section{References}

1. Wang, F., Liu, S.H., Cui, Y.X. (2021) Reflections on New Engineering Subject Construction in Local Engineering Colleges under the Background of Engineering Education Accreditation. Journal of Higher Education., 03: 63-66.

2. Cang, H., Yu, G.Y., Xu J.Y., Chen, S. (2020) The Teaching Reform Practice of the "RedYellow-Green" Three-color Fusions Curriculum System of Introduction to Chemical Engineering Course. Shandong Chemical Industry., 23: 156 -157.

3. Liu, S.F., Huang, T., Li, S., Sun, Z.L. (2020) Research on Teaching Reform of Introduction to Civil Engineering Based on Innovation Ability Training. Science and Technology Innovation Guide., 17: 175,180 .

4. Zhu, Y.P., Zhang, X.J. (2021) Construction and Practice of Engineering Training System Based on New Engineering. Experimental Technology and Management., 01: 08-11.

5. Shi, D.H., Ji, C. (2019) Research on Hybrid Teaching Scheme of New Energy Vehicle 
6. Technology Course Based on Rain Classroom.

Education Modernization., 06: 113-115. 